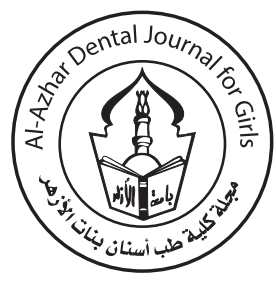

\title{
Influence of Coronal Pre-Flaring on the Apical Transportation and Dentinal Damage after Preparation of Curved Root Canals
}

\section{Lamia'a G. Mohammed ${ }^{1 *}$, Wael H. Kamel ${ }^{2}$, Mohsen M. Nour El Din ${ }^{3}$}

Codex : 08/2001

azhardentj@azhar.edu.eg

http://adjg.journals.ekb.eg

DOI: $10.21608 /$ adjg.2019.7705.1094

\section{KEYWORDS}

EndoStar, OneShape, pre-flaring, ProTaper Next.

\begin{abstract}
Purpose: This study was designed to evaluate the influence of pre-flaring on the apical transportation and dentinal damage after preparation of curved root canals using EndoStar (ES5), OneShape (OS) and ProTaper Next (PTN) systems. Material and Methods: Hundred and twenty human mandibular first molars were selected. Pre-operative imaging by $\mathrm{CBCT}$ was done for measurement of apical transportation of mesio-buccal root canals then saved. The specimens were grouped into: Group I: Instrumented by ES5 files; Group II: by OS single file; and Group III: by PTN files. Each group was subdivided into subgroups: A: Instrumented without pre-flaring; and B: pre-flared before instrumentation. After instrumentation, all specimens were scanned under the same way as the pre-operative scan and data were saved on the software for evaluation of apical transportation. Roots were sectioned perpendicular to long axis at 3, 6 and $9 \mathrm{~mm}$ from the apex and viewed under SEM for detection of any defect arise from lumen outwards. The significance was set at $\mathrm{P}<0.05$. Results: All values of apical transportation at level $2 \mathrm{~mm}$ from apex were positive that indicated direction of transportation toward mesial direction of root canal, whereas at level $4 \mathrm{~mm}$ from apex were negative that indicated direction of transportation toward distal direction of root canal. In dentinal defects at $6 \mathrm{~mm}$, the higher percent of cracks was noted in OS and the lowest for PTN. Conclusions: Pre-flaring of root canal reduces the apical transportation and dentinal defects when curved root canals were prepared with $\mathrm{Ni}-\mathrm{Ti}$ instruments.
\end{abstract}

- Paper extracted from MSc thesis titled: Influence of Coronal Pre-Flaring on the Apical Transportation and Dentinal Damage after Preparation of Curved Root Canals.

1. Dentist in Ministry of Health

2. Professor and Head of Endodontic Department, Faculty of Dental Medicine for Girls, Al-Azhar University

3. Professor of Endodontics, Faculty of Dental Medicine for Girls, Al-Azhar University

* Corresponding author Email: lolo_gm2003@hotmail.com 


\section{INTRODUCTION}

The main objectives of root canal procedure are adequate enlargement, shaping, cleaning and disinfection of all pulpal spaces, along with obturation of these spaces with an acceptable filling material ${ }^{(1)}$. One of the most important factors that affect quality of root canal treatment is the anatomy of the root canal, specially the apical third curvature. Difficulty to achieve the objectives of biomechanical preparation of apically curved canals by using stainless steel hand instruments lead to introduction of $\mathrm{Ni}-\mathrm{Ti}$ instruments, which have additional advantages over stainless steel instruments ${ }^{(2)}$. They are quick, safe and are more accuracy oriented with mainly having lower risk of procedural errors when compared to stainless steel hand instruments ${ }^{(3)}$. The apical third is the region most susceptible to accidents such as apical transportation, ledge formation and perforations during instrumentations ${ }^{(4)}$. Apical Transportation is an unfavorable error mainly produced during mechanical preparation of curved root canals, disturbs the cleaning of the entire extension of root canal space properly, resulting in failure of the infection control, and therefore can affect the prognosis of endodontic therapy ${ }^{(5-7)}$.

Many authors stated in their study that the durability of the tooth structure remaining after endodontic procedure is proportioned directly to the root dentin thickness remaining. The rotary $\mathrm{Ni}-\mathrm{Ti}$ instruments could potentially cause defects in canal dentin walls which may act as areas of stress concentration and crack initiation ${ }^{(8)}$. These Ni-Ti instruments have a dangerous defect on canal dentin wall in the form of cracks and craze lines. Craze lines can later results in vertical root fracture if the tooth is subjected to repeated stresses from further endodontic procedures ${ }^{(9)}$. These Ni-Ti instruments have been modified in their design and metallurgy to improve their mechanical properties, as well as decrease formation of these defects.

Coronal pre-flaring gives rise to the formation of Straight line access (SLA) which gives an unob- structed or straight path from the occlusal to the apical end or the first curvature of the canal. This not only reduces unnecessary deflection of the file and allows better operator control over the instrument, but also improves tactile sense, increases the accuracy of working length (WL) determination and aids in adequately achieving the desired apical working width $^{(10)}$

Presence of root canal curvatures make endodontic preparation more difficult, where there is a tendency to develop procedural errors, such as apical transportation and dentinal damage ${ }^{(11)}$. Coronal pre-flaring may overcome these errors, combined with different modified Ni-Ti rotary systems.

\section{MATERIAL AND METHODS}

\section{Specimen selection:}

A total of one hundred and twenty freshly extracted human permanent mandibular first molars, were used in this study. Teeth were collected from the oral surgery department, Faculty of Dental Medicine for Girls, Al-Azhar University. Ethical approval for the use of extracted human teeth was obtained in accordance with guidelines from research ethics committee, Faculty of Dental Medicine for Girls, Al-Azhar University. The external surfaces of all the specimens were inspected to ensure intact teeth without any pre-existing external defects or cracks. Teeth with open apices, fractures, internal resorption or complex canal anatomy were excluded, and pre-operative radiographic films were taken to confirm the criteria of specimen selection.

\section{Specimen preparation:}

The collected teeth were stored in $5.25 \mathrm{NaOCl}$ solution for 30 minutes at room temperature for surface disinfection. All crowns were sectioned at 3 $\mathrm{mm}$ coronal to the cemento-enamel junction (CEJ) and the distal root of all specimens were separated at the furcation level. Mesiobuccal canals were checked for apical patency with \#10 K-file to establish the working length. 
Pre-operative apical transportation measurement by using CBCT:

All roots were embedded in a rubber base impression material that were placed in plastic dental arches to close approximation of the pre-operative and post-operative images. All specimens were embedded in impression material to the level of CEJ. To determine the pre-operative criteria of the root canals, the plastic dental arches which contained the mesial roots were imaged by three dimensional i-CAT imaging system. All data were viewed and measurements were performed by the invivo 5 software. In all samples, multiple steps were followed to standardize the measurement of pre and postoperative apical transportation. The images were saved on software for later comparison.

\section{Grouping of specimen:}

Specimens were numerically coded and grouped into three main groups according to rotary $\mathrm{Ni}-\mathrm{Ti}$ systems used in canal: Group I: Instrumented with EndoStar (ES5) (Poldent, Warsaw, Poland) files system; Group II: Instrumented with OneShape (OS) (Micro-Mega, Besancon Cedex, France) single file system; Group III: Instrumented with ProTaper Next (PTN) (Densply Mallifer, Switzerland) files system. Each main group was subdivided into two subgroups, A and B according to the effect of preflaring: Subgroup A: Specimens were instrumented without coronal pre-flaring. Subgroup B: Specimens were instrumented with coronal pre-flaring using LA axxess burs (SybronEndo, Orange, Canada). After instrumentation, each subgroup was measured for apical transportation (AT) and dentinal damage (DD).

\section{Instrumentation of the specimen:}

The root canals were thoroughly irrigated with $2 \mathrm{ml}$ of freshly prepared $2.6 \%$ sodium hypochlorite $(\mathrm{NaOCl})$ solution using 31 gauge navi tip irrigation needle that was inserted $2 \mathrm{~mm}$ short of final working length, then $2 \mathrm{ml}$ of $17 \%$ EDTA was used for $1 \mathrm{~min}$ to remove the smear layer followed by 10 $\mathrm{ml}$ of distilled water as final flush to prevent erosion of the dentinal tubules. The flutes of every instrument were cleaned with gauze wetted by alcohol after each picking motion to remove debris. Each file was inspected after each instrumentation for distortion. In group I, II and III subgroup A (without pre-flaring), the rotary Ni-Ti files systems ES5,OS and PTN were used respectively in crown down manner for root canal preparation according to manufacturer instructions. For groups I, II, and III subgroup B, all specimens were previously preflared. LA Axxess burs were used for pre-flaring the coronal and middle root canal thirds. Then the canal was irrigated and prepared according to the previous manner. The apical foramen was gauged with \#25 K file, in which the file was snugly fit the canals were shaped.

\section{Post-operative measurement of apical transpor- tation:}

After instrumentation, all specimens were scanned the same way as the pre-operative scan and data were saved on the software for their analysis. The amount of apical transportation was determined by comparing pre and post-operative mesial and distal dimensions.

\section{Evaluation of apical transportation:}

The amount of apical transportation was determined by measuring the shortest distance from the edge of the pre instrumented canal to the periphery of the root (mesial and distal) and then comparing these measurements with the same measurements obtained from the instrumented images. The positive values indicated direction of transportation in a mesial direction (outer wall of the canal), and the negative values indicated direction of transportation in a distal direction (inner wall of the canal).

\section{Measurement of dentinal damage:}

After instrumentation, and measurement of apical transportation, each specimen was sectioned perpendicular to their long axis at 3,6 and $9 \mathrm{~mm}$ 
from the apex. The cut sections were stored in $(0.9 \% \mathrm{NaCl})$ until further processing. Each section was viewed under SEM magnification (X80) to examine the presence of microcracks.

\section{Statistical analysis}

A software program SPSS 19 was used for performing statistical analysis. As data related to transportation at $2 \mathrm{~mm}$ level were parametric, significance of the difference between different systems within the same pre-flaring status was evaluated using ANOVA test, followed by Tukey's post hoc test when ANOVA indicated a significant difference. Independent $t$ test was used to compare between mean values with and without pre-flaring. All data related to transportation at $2 \mathrm{~mm}$ level were positive that indicated for the mesial direction of transportation. As data related to transportation at $4 \mathrm{~mm}$ level were non-parametric, significance of the difference between different systems within the same pre-flaring status was evaluated using Kruskall Wallis test, followed by Tukey's post hoc test when Kruskall Wallis indicated a significant difference. Mann Whitney U test was used to compare between mean values with and without pre-flaring. All data related to transportation at $4 \mathrm{~mm}$ level were negative and thus indicated for the distal direction of transportation. As for data related to dentinal defects, the descriptive statistics were expressed as frequency and percent. Chi-square test was used to determine the difference among the groups. The $P$ value of significance level was set at $P<0.05$.

\section{RESULTS}

\section{Apical Transportation (2mm):}

\section{A. Comparison between systems:}

On comparing the different systems without pre-flaring group, ES5 system recorded the highest mean value $(0.120 \pm 0.083)$, whereas the lowest mean value was recorded in PTN system $(0.011 \pm$ $0.046)$, while OS recorded $(0.028 \pm 0.134)$. ANOVA test revealed that this difference was not statistically significant $(p=0.068)$. In the pre- flaring group, the highest mean value was recorded in ES5 system $(0.049 \pm 0.080)$, whereas the lowest mean value was recorded in PTN system $(0.001 \pm 0.25)$, while OS recorded $(0.005 \pm 0.015)$. ANOVA test revealed that this difference was not statistically significant $(p=0.122)$.

\section{B. Effect of pre-flaring:}

In ES5 system, a higher mean value was recorded without pre-flaring $(0.120 \pm 0.083)$ while with pre-flaring recorded a value of $(0.049 \pm 0.080)$. Independent $t$ test revealed no significance difference between values recorded with or without preflaring ( $p=0.158)$. In OS system, a higher mean value was recorded without pre-flaring $(0.028 \pm 0.134)$ while with pre-flaring recorded a value of $(0.005 \pm$ 0.015). Independent t test revealed no significance difference between values recorded with or without pre-flaring ( $p=0.592)$. In PTN system, a higher mean value was recorded without pre-flaring $(0.011$ $\pm 0.046)$ while with pre-flaring recorded a value of $(0.001 \pm 0.025)$. Independent $t$ test revealed no significance difference between values recorded with or without pre-flaring ( $p=0.696)$.

\section{Apical Transportation (4mm):}

\section{A. Comparison between systems:}

On comparing the different systems without pre-flaring group, ES5 system recorded the highest mean value $(0.31 \pm 0.06)$, whereas the lowest mean value was recorded in PTN system $(0.06 \pm$ $0.12)$, while OS recorded $(0.14 \pm 0.19)$. Kruskall Wallis test revealed that this difference was statistically significant $(p=0.001)$. In pre-flaring group, the highest mean value was recorded in ES5 system $(0.08 \pm 0.10)$, whereas the lowest mean value was recorded in PTN $(0.02 \pm 0.20)$, while OS system recorded $(0.06 \pm 0.11)$. Kruskall Wallis test revealed that this difference was not statistically significant $(p=0.223)$.

\section{B. Effect of pre-flaring:}

In ES5 system, a higher mean value was recorded without pre-flaring $(0.31 \pm 0.06)$ while with pre- 
flaring recorded $(0.08 \pm 0.10)$. Mann Whitney U test revealed a significance difference between values recorded with or without pre-flaring $(p=0.0021)$. In OS system, a higher mean value was recorded without pre-flaring $(0.14 \pm 0.19)$ while with pre-flaring recorded $(0.06 \pm 0.11)$. Mann Whitney $U$ test revealed a significance difference between values recorded with or without pre-flaring $(p=0.031)$. In PTN system, a mean value was recorded without pre-flaring $(0.06 \pm 0.12)$ while with pre-flaring recorded $(0.02 \pm 0.2)$. Mann Whitney U test revealed non significance difference between values recorded with or without pre-flaring $(p=0.89)$.

\section{Dentinal Damage (Cracks):}

\section{A. Comparison of number/percentage of cracks in different systems in each of the pre-flaring status:}

In without pre-flaring groups, at $3 \mathrm{~mm}$ the higher percent was noted in ES5 (75\%), followed by OS (50\%), then the lowest was for PTN (20\%). At 6 $\mathrm{mm}$, the higher percent of cracks was noted in OS (85\%) followed by ES5 (80\%), and the lowest for PTN (30\%). At $9 \mathrm{~mm}$, the highest percent of cracks was noted for ES5 (60\%), followed by OS (45\%), the lowest record was for PTN (15\%). Chi square test revealed that the difference between systems was statistically significant $(p=0.0344)$. In preflaring groups, at $3 \mathrm{~mm}$, the highest percent was recorded for ES5 (60\%), followed by OS (40\%), and the lowest percent was recorded for PTN (20\%). A $6 \mathrm{~mm}$, the highest percent was recorded for OS (75\%), followed by ES5 (65\%) and the lowest for PTN (25\%). At $9 \mathrm{~mm}$, a higher number of cracks was noted in ES5 (45\%), followed by OS (25\%) and the lowest for PTN (10\%). Chi square test revealed that the difference between systems was not statistically significant $(p=0.83)$.

\section{B. Effect of pre-flaring:}

In ES5 system, without pre-flaring a highest percent of cracks was recorded at $6 \mathrm{~mm}(80 \%)$, followed by $3 \mathrm{~mm}(75 \%)$ whereas the lowest was recorded at $9 \mathrm{~mm}(60 \%)$. With Flaring, highest percent of cracks was recorded at $6 \mathrm{~mm}(65 \%)$, followed by $3 \mathrm{~mm}(60 \%)$ whereas the lowest was recorded at 9 $\mathrm{mm}(45 \%)$. Chi square test revealed no significance difference between percent of cracks recorded with or without pre-flaring $(p=0.274)$. In OS system, without pre-flaring, a highest percent of cracks was recorded at $6 \mathrm{~mm}(85 \%)$, followed by $3 \mathrm{~mm}(50 \%)$ whereas the lowest was recorded at $9 \mathrm{~mm}(45 \%)$. With flaring, highest percent of cracks was recorded at $6 \mathrm{~mm}(75 \%)$, followed by $3 \mathrm{~mm}(40 \%)$ whereas the lowest was recorded at $9 \mathrm{~mm}(25 \%)$. Chi square test revealed no significant difference between percent of cracks recorded with or without pre-flaring $(p=0.365)$. In PTN system, without pre-flaring a highest percent of cracks was recorded at $6 \mathrm{~mm}$ (30\%), followed by $3 \mathrm{~mm}(25 \%)$ whereas the lowest was recorded at $9 \mathrm{~mm}(15 \%)$. With flaring, a highest percent of cracks was recorded at $6 \mathrm{~mm}(25 \%)$, followed by $3 \mathrm{~mm}(20 \%)$ whereas the lowest was recorded at $9 \mathrm{~mm}(10 \%)$. Chi square test revealed no significant difference between percent of cracks recorded with or without pre-flaring $(p=0.48)$ (table 1, figure 1).

Table 1: Comparison of number/percentage of cracks in different systems with/without pre-flaring (Chi square test):

\begin{tabular}{|c|c|c|c|c|}
\hline System & Pre-flaring & $\begin{array}{c}3 \mathrm{~mm} \\
\mathrm{n}(\%)\end{array}$ & $\begin{array}{c}6 \mathrm{~mm} \\
\mathrm{n}(\%)\end{array}$ & $\begin{array}{c}9 \mathrm{~mm} \\
\mathrm{n}(\%)\end{array}$ \\
\hline \multirow{4}{*}{ ES5 } & Without & $15(75 \%)$ & $16(80 \%)$ & $12(60 \%)$ \\
\cline { 2 - 5 } & With & $12(60 \%)$ & $13(65 \%)$ & $9(45 \%)$ \\
\cline { 2 - 5 } & $\mathrm{X}^{2}$ & \multicolumn{3}{|c|}{2.588} \\
\cline { 2 - 5 } & $\mathrm{P}$ & \multicolumn{3}{|c|}{$0.274 \mathrm{~ns}$} \\
\hline \multirow{4}{*}{ OS } & Without & $10(50 \%)$ & $17(85 \%)$ & $9(45 \%)$ \\
\cline { 2 - 5 } & With & $8(40 \%)$ & $15(75 \%)$ & $5(25 \%)$ \\
\cline { 2 - 5 } & $\mathrm{X}^{2}$ & \multicolumn{3}{|c|}{2.015} \\
\cline { 2 - 5 } & $\mathrm{P}$ & \multicolumn{3}{|c}{$6.365 \mathrm{~ns}$} \\
\hline \multirow{4}{*}{ PTN } & Without & $5(25 \%)$ & $6(30 \%)$ & $3(15 \%)$ \\
\cline { 2 - 5 } & With & $4(20 \%)$ & $5(25 \%)$ & $2(10 \%)$ \\
\cline { 2 - 5 } & $\mathrm{X}^{2}$ & \multicolumn{3}{|c}{$0.48 \mathrm{~ns}$} \\
\cline { 2 - 5 } & $\mathrm{P}$ & \multicolumn{3}{|c}{} \\
\hline
\end{tabular}

Significance level $P<0.05, n s=$ non-significant 


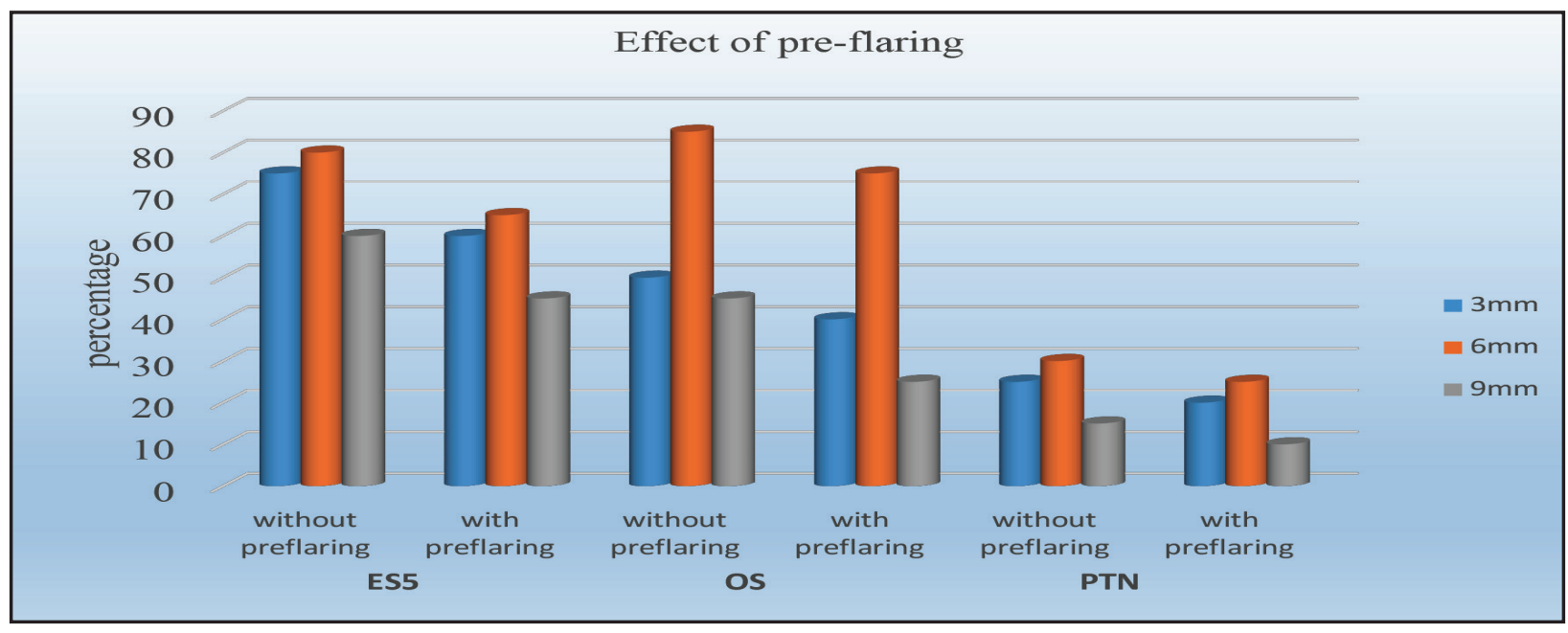

Figure (1) Column chart showing percentage of cracks in different systems with or without pre-flaring.

\section{DISCUSSION}

The main goals of root canal preparation are adequate cleaning and shaping of the root canal system while protecting the original shape of the canal without creation of any procedural errors such as instrument fractures, ledges, zipping and canal transportation $^{(1)}$. The introduction of rotary Ni-Ti instruments has sharply reduced these clinical mishaps, facilitated the effectiveness of instrumentation and the speed of cleaning and shaping procedures even in the most severely curved canals ${ }^{(3)}$. The mesiobuccal canals of the extracted human mandibular molars were selected for their wide range of curvature, and having rounder cross sections ${ }^{(12)}$, and they also offer the advantage of three dimensional nature of the root canal curvature. The curvatures of all root canals ranged between $20^{\circ}$ and $35^{\circ}$ according to the Schneider's technique ${ }^{(13)}$ and the radii were $<15 \mathrm{~mm}$, determined by the Estrela's method ${ }^{(14)}$ based on the preoperative CBCT.

$\mathrm{Ni}-\mathrm{Ti}$ instruments were designed to make the ability to protect the original shape of curved canals better after their preparation ${ }^{(15-17)}$. EndoStar instruments consist of five machine tools made of Ni-Ti alloy and marked with blue stripes. The number of stripes corresponds to the tool number. Tools in cross-section have the shape of a modified $\mathrm{S}$ with two $90^{\circ}$ cutting angles, have a prolonged weave and a rounded tip ${ }^{(18)}$. ProTaper Next was introduced as a system designed with the most recent technological advancements including progressive percentage tapers on a single file, the offset design and M-wire technology to make the root canal shaping easier ${ }^{(19)}$. A revolution approach of using single file in completing the root canal instrumentation presented a new perspective for Ni-Ti rotary file usage technique. OneShape file system is made of a Ni-Ti alloy and is used in continuous clockwise rotation. The unique design of OS instrument incorporates three different cross-sectional areas along the active length of the file, which offers an optimal and improved cutting action in three zones of the root canal $^{(20)}$. Preparation of the coronal third of root canals is an important step for the dentin interferences removal, ensuring straight access to the canals for easier cleaning and shaping, and proper filling of the root canals ${ }^{(21)}$. The coronal third should be safely prepared to maintain the integrity of the canal walls without risking the perforation ${ }^{(22)}$. Titanium nitride treated stainless steel LA Axxess burs, with safe ended tips have been introduced, which promise a safer and more effective pre-flaring compared to the conventional drills and files ${ }^{(23)}$. 
In both groups of pre-flaring condition, at both levels of $2 \mathrm{~mm}$ and $4 \mathrm{~mm}$, the results showed that the highest amount of mean value of apical transportation was recorded in ES5 file system compared to OS \& PTN file system. The lowest mean value was recorded in PTN file system, there was no significant difference in the transportation among the file systems. This could be attributed to the different cross sectional designs among each system. EndoStar files have a small S-Shaped cross-section with 2 cutting blades, aiming to achieve better cutting ability of dentin and to enhance the flexibility of the instrument compared to triangular cross-sections ${ }^{(18)}$. Asymmetrical cross-section of OS, triangular at apical and transition in the middle might improve the flexibility of the file and reduce the applied stress to its working blade, making it easier for canal negotiation. This result is in agreement with the previous study comparing between $\mathrm{S}$ shaped and triangular cross sections ${ }^{(24)}$. ProTaper Next showed lower value in different groups and levels. This could be due to their cross-sectional design ${ }^{(17,25)}$, or due to the type of alloy used for its manufacturing (M-wire) $)^{(26)}$. The use of PTN file caused less canal transportation than the use of ES5, this difference between them might be due to the difference in their manufacturing and design features. The two files are made of different metal alloys. ProTaper Next is constructed from M-wire and ES5 from conventional Ni-Ti. Instruments that are made of new alloys (CM-wire, M-wire) produce almost no transportation ${ }^{(27)}$. This could explain the smaller amount of transportation induced by PTN in comparison with ES5. The use of PTN showed less canal transportation than OS, but No statistical difference was found and they were nearly equal to each other, This is in agreement with a study that showed that canal transportation was similar among Wave One, PTN, TF adaptive, and $\mathrm{OS}^{(28)}$. In addition, another study using CBCT imaging, found that PTN X2 and OS preserved root canal curvature equally well and had the same result of canal transportation during the instrumentation of mesial canals of permanent mandibular molars ${ }^{(29)}$. However, another study showed that PTN resulted in more apical transportation than did OS. The opposition between those results and ours may reflect differences in the methodology of the studies ${ }^{(30)}$. In terms of apical transportation directions, in all groups and both pre-flaring status, transportation prone to occur on the distal surface of the canal curvature at the $4 \mathrm{~mm}$ level and the mesial surface of the canal curvature at the $2 \mathrm{~mm}$ level. This result lead to the probability of increased straightening tendencies of the instruments in a curved canal, as proved by many authors. This was in agreement with the same results done by some authors ${ }^{(31)}$. The positive direction at $2 \mathrm{~mm}$ with no significance, could be revealed to the tip design. The compared systems are characterized by non-cutting, pilot tip, which slides over the wall of the canal, and the preparation is carried out by the distal portion of the instrument. At $4 \mathrm{~mm}$ level, all instrumentation systems caused transportation, especially towards the inner part of the curvatures, and the amount was increased concurrently with the cross-section of the instrument. This could be also due to the taper of instruments ${ }^{(6)}$. Regardless to systems used, the pre-flaring groups showed less values than groups not pre-flared among both levels $(2 \mathrm{~mm}$ and $4 \mathrm{~mm})$. Performing coronal enlargement has been confirmed to be definitive procedures to allow using of Ni-Ti rotary instruments in curved canals safely as they provide the files a straighter path to the apical end of the canal, while reducing any coronal obstacles or change in direction of the files apically. In addition, pre-flaring tends to diminish procedural errors such as ledge formation and apical transportation ${ }^{(32)}$.

In both pre-flaring status, the result showed that the highest number of cracks was recorded in ES5 at level of $3 \mathrm{~mm}$, whereas the OS group recorded the highest number of cracks at level of $6 \mathrm{~mm}$ and $9 \mathrm{~mm}$. The lowest number of cracks was recorded for PTN among the three levels. All records were not statistically significant. One of the susceptible causes of high number of cracks at apical level was high curvature of root canal, which could results in increase stresses applied on the instrument because of 
contact between the root canal wall and instrument, which could leads to unfavourable outcomes including higher risk of apical cracking ${ }^{(30)}$. More incidence of root microcracks were observed in apical $3 \mathrm{~mm}$ section suggesting maximal stress concentration in apical third of root canals by rotary instrumentation during canal preparation. The higher number of cracks of ES5 compared with OS at 3mm could be attributed to the cross sectional design. EndoStar at apical portion have $\mathrm{S}$ shaped cross section that had high cutting efficiency, compared with triangular cross section of OS at the apical part. Multiple files used for preparation of apical third with ES5 compared with preparation with single file OS may be another contributing factor. By contrast, a previous study ${ }^{(33)}$, used an identical methodology and observed that the multiple-files rotary system caused a higher number of cracks on the apical root surface and in the canal wall in comparison with single-file rotary systems. However; another study ${ }^{(34)}$, proved that root canals prepared with multiple-files systems showed less dentin defect than single file systems where only, one instrument causes more stress on dentin root canal surface leading to crack formation. Multiple-files systems showed less dentin damage in rotation motion ${ }^{(28)}$. The higher number of cracks at level of $6 \mathrm{~mm}$ was recorded in OS, compared with ES5 group. This could be attributed to the unique design of OS. OneShape has asymmetrical crosssection over entire length and variable pitch, noncutting safety tip. Transition zone of the OS file have higher cutting efficiency that cracks were produced at the middle level of the root canal ${ }^{(35)}$. This result could be attributed to convergence of file (taper) in agreement with a study which ${ }^{(36)}$, stated that the file taper could be a factor in dentin defect formation. It was concluded that the more root dentin that is removed the more likely a root is to fracture ${ }^{(33)}$. Both ES5 and OS have constant taper along the file length, ES5 has constant $4 \%$ taper while OS has $6 \%$ constant taper. The reason for low number of cracks in PTN file system along the entire length of root canal may be due to its decentered rectangular design which produces a snake-like motion, which reduces the lock-in effect, by decreasing the contact between the file and the dentin root canal surface ${ }^{(17)}$. Alternating taper, which decreasing the screwing effect could be another contributing factor for less micro-cracks were associated in PTN group. In addition, PTN files are manufactured from M-wire $\mathrm{Ni}$-Ti alloy which shows more flexibility than those manufactured from conventional Ni-Ti alloy (ES5 and OS). All the instrumentation systems showed decreased number of cracks among different levels. This may be due to the effect of pre-flaring on reduction of canal curvature that leads to decrease stresses on instrument when come in contact with root canal wall. All systems compared in this study have an active rotation motion that may result in high stress concentration in root canal walls and may results in dentin defect formation ${ }^{(33)}$. This could be a reason of why all root canals showed crack formation in different levels.

\section{CONCLUSIONS}

Under the condition of this study, it was concluded that:

- Coronal pre-flaring of root canal has an effect on reducing the apical transportation when curved root canals were prepared with tested with rotary Ni-Ti instruments.

- PTN is promising instrument in shaping of curved root canal and was safe to be used either with or without pre-flaring.

- Coronal pre-flaring of the curved root canal has an impact on reducing the incidence of dentinal defect, mainly in root canals prepared with PTN.

\section{REFERENCES}

1. Schilder H. Cleaning and shaping the root canal. Dent Clin North Am. 1974; 18:269-96.

2. Schäfer E. Shaping ability of Hero 642 rotary nickeltitanium instruments and stainless steel hand K-Flexofiles in simulated curved root canals. Oral Surg Oral Med Oral Pathol Oral Radiol Endod 2001; 92: 215-20. 
3. Guelzow A, Stamm O, Martus P, Kielbassa AM. Comparative study of six rotary nickel-titanium systems and hand instrumentation for root canal preparation. Int Endod J 2005; 38: 743-52.

4. Jeon HJ, Paranjpe A, Ha JH, Kim E, Lee W, Kim HC. Apical enlargement according to different pecking times at working length using reciprocating files, J Endod. 2014; 40: $281-4$.

5. Hartmann MS, Fontanella VR, Vanni JR, Fornari VJ, Barletta FB. CT evaluation of apical canal transportation associated with stainless steel hand files, oscillatory technique and protaper rotary system. Braz Dent J. 2011; 22: 288-9.

6. Schäfer E, Vlassis M. Comparative investigation of two rotary nickel-titanium instruments: ProTaper versus RaCe. Part 1. Shaping ability in simulated curved canals. Int Endod J. 2004; 37: 229-38.

7. Vaudt J, Bitter K, Neumann K, Kielbassa AM. Ex vivo study on root canal instrumentation of two rotary nickeltitanium systems in comparison to stainless steel hand instruments. Int Endod J. 2009; 42: 22-33.

8. Ganesh A, Venkateshbabu N, John A, Deenadhayalan G, Kandaswamy D. A comparative assessment of fracture resistance of endodontically treated and re-treated teeth: An in vitro study. J Conserv Dent. 2014; 17: 61-4.

9. Shemesh H, Bier CA, Wu MK, Tanomaru-Filho M, Wesselink PR. The effects of canal preparation and filling on the incidence of dentinal defects.Int Endod J. 2009; 42: 208-13.

10. Peters OA, Peters CI, Basrani B. Cleaning and Shaping the Root Canal System, part I: The Core Science of Endodontics, Cohen's pathways of the pulp, 11th ed. 2016: 209-79.

11. Weine FS, Kelly RF, Lio PJ. The effect of preparation procedures on original canal shape and on apical foramen shape. J Endod. 1975; 1: 255-62.

12. Wu M, Wesselink P, and Walton R. Apical terminus location of root canal treatment procedures. Oral Med Oral Pathol \& oral Radiol Endod. 2000; 89: 99-103.

13. Schneider SW. A comparison of canal preparations in straight and curved root canals. Oral Surg Oral Med Oral Pathol 1971; 32: 271-5.

14. Estrela C, Bueno MR, Sousa-Neto MD, Pécora JD. Method for Determination of Root Curvature Radius Using ConeBeam Computed Tomography Images. Braz Dent J .2008; 19: 114-8.
15. Thompson SA. An overview of nickel-titanium alloys used in dentistry. Int Endod J. 2000; 33: 297-310.

16. Stoeckel D. and Yu W; Superelastic Ni-Ti wire, Wire J Int.1991; March: 45-50.

17. Haapasalo M, Shen Y. Evolution of nickel-titanium instruments: from past to future. Endod Topics. 2013; 29: 3-17.

18. Radwański M, Łęski M, Pawlicka H. Shaping ability of three modern rotary instruments in simulated L-curved canals. J Stoma. 2015; 68: 240-54.

19. Dhingra A, Banerjee S, Aggarwal N, Yadav V. Canal Shaping with ProTaper Next: An Ex Vivo Study. Transportation. 2014; 1(X2):Y1-Y2.

20. Gernhardt CR. OneShape - a single file Ni Ti system for root canal instrumentation used in continuous rotation. Endodontic Practice Today. 2013; 7: 211-6.

21. Sharma SA, Tyagi SP, Sinha DJ, Singh UP, Chandra $\mathrm{P}$, Kaur G. Influence of cervical pre-flaring using different rotary instruments on the accuracy of apical file size determination: A comparative in-vitro study. J Conserv Dent. 2014; 17: 575-8.

22. Royer J, Cord C B, de Melo T F. Analysis of four instruments used in cervical root pre-flaring regarding the area and thickness of furcation area. Odonto 2015; 23: 37-45.

23. Sanfelice CM, Costa FB, Só MVR, Vier-Pelisser F, Bier CAS, Grecca FSG. Effects of four instruments on coronal pre-enlargement by using cone beam computed tomography. J Endod 2010; 36: 858-61.

24. Saberi EA, Mohammadi A, Ebrahimipour S, Baniasadi S. In-vitro Comparison of NiTi Tee, RaCe and Protaper Instruments in Dentinal Crack Formation. J Dent Mater Tech 2017; 6: 152-8.

25. Gambarini G, Gerosa R, De Luca M, Garala M, and Testarelli L. Mechanical properties of a new and improved Nickel-titanium alloy for endodontic use: an evaluation of file flexibility. Oral Surg Oral Med Oral Pathol Oral Radiol Endod. 2008; 105: 798-800.

26. Alrahabi M and Alkady A. Comparison of root canal apical transportation associated with Wave One, ProTaper Next, TF, and OneShape nickel-titanium instruments in curved canals of extracted teeth: A radiographic evaluation. The Saudi Journal for Dental Research. 2017; 8: 1-4.

27. Bürklein S and Schäfer E. Critical evaluation of root canal transportation by instrumentation. Endodontic Topics 2013; 29: 110-24. 
28. Pedullà E, Genovesi F, Rapisarda $\mathrm{S}$, La Rosa GR, Grande NM, Plotino G, Adorno CG. Effects of 6 Single-File Systems on Dentinal Crack Formation. J Endod. 2017; 43: 456-61.

29. Capar I D, Arslan H,Akcay M, Uysal B. Effects of ProTaper Universal, ProTaper Next, and HyFlex instruments on crack formation in dentin. J Endod 2014; 40:1482-4.

30. Li ML, Liao WL and Cai HX. A micro-computed tomographic evaluation of dentinal microcrack alterations during root canal preparation using single-file Ni-Ti systems. Experimental and Therapeutic Medicine. 2018; 15: 494-9.

31. Uzunoglu E, Turker SA. Comparison of Canal Transportation, Centering Ratio by Cone-beam Computed Tomography after Preparation with Different File Systems. J Contemp Dent Pract. 2015; 16: 360-5.

32. Borges AH, Damião MS, Pereira TM, Filho GS, MirandaPedro FL, de Oliveira da Rosa WL, Piva E, Guedes OA.
Influence of Cervical Pre-flaring on the Incidence of Root Dentin Defects. J Endod. 2018; 44: 286-91.

33. Liu R, Hou B X, Wesselink P R, Wu M K, Shemesh H. The incidence of root microcracks caused by 3 different single-file systems versus the ProTaper system. J Endod 2013; 39: 1054-6.

34. Priya NT, Veeramachaneni Chandrasekhar SA, Tummala M, Raj TP, Badami V, Kumar P, et al. "Dentinal microcracks after root canal preparation" A comparative evaluation with hand, rotary and reciprocating instrumentation. JCDR. 2014; 8: ZC70-4.

35. Bürklein S, Benten S, Schäfer E. Shaping ability of different single-file systems in severely curved root canals of extracted teeth. Int Endod J. 2013; 46: 590-7.

36. Bier CAS, Shemesh H, Tanomaru-Filho M, Wesselink PR, Wu M-K. The ability of different nickel-titanium rotary instruments to induce dentinal damage during canal preparation. J Endod 2009; 35: 236-8. 